\title{
Europese financiële transactietax - verhoging van de stabiliteit?!
}

Meiqi de Vries en Natalie Speet

\begin{abstract}
SAMENVATTING De Europese Commissie heeft een voorstel gepubliceerd voor een Europese financiële transactiebelasting met als belangrijkste doelstelling een meer stabiele financiële sector. Een analyse van economische studies laat niet eenduidig zien of de invoering van deze transactiebelasting daadwerkelijk leidt tot een meer stabiele financiële sector in Europa. Daarentegen leidt de transactiebelasting hoogstwaarschijnlijk wel tot hogere transactiekosten en concurrentieverstoringen als gevolg van een sterke daling in het transactievolume. Dit resultaat ondersteunt de voorlopige keuze van Nederland om voor een nationale bankenbelasting te kiezen. Echter, met het oog op de harmonisatie van nationale wetgevingen kan het in de toekomst voor Nederland het overwegen waard zijn om toch deel te nemen aan een EU-brede belasting.
\end{abstract}

\section{RELEVANTIE VOOR DE PRAKTIJK Belangrijke wensen van de EU zijn dat banken} hun risicobeheersing versterken en dat de volatiliteit van de financiële markten afneemt. De financiële transactietax moet hierbij een belangrijke rol spelen. Dit artikel laat zien dat de bestaande economische literatuur geen eenduidigheid biedt over het effect van de invoering van een dergelijke belasting op de stabiliteit van de Europese financiële sector. De eventuele deelname van Nederland aan deze belasting zou niet gebaseerd mogen worden op dit argument. Er zijn niettemin belangrijke voordelen, zoals het harmoniseren van nationale wetgevingen voor financiële transacties in EUcontext (hetgeen toeneemt naar mate meer EU-landen deelnemen aan de financiële transactiebelasting) en de maatschappelijke wens om de financiële sector te belasten. Vanuit economisch oogpunt moeten deze voordelen van de financiële transactietax worden afgewogen tegen de extra kosten die gemoeid zijn bij de implementatie van de financiële transactietax.

\section{Inleiding en probleemstelling}

Op 28 september 2011 heeft de Europese Commissie het voorstel gepubliceerd een EU-brede belasting in te voeren waarmee financiële transacties worden belast in de deelnemende lidstaten. Door de langdurige onenigheid over de vormgeving van de Europese financiële transactiebelasting (FTT) in de elf deelnemende lidstaten ${ }^{1}$ en de potentiële effecten op de financiële markten komt de Europese Commissie waarschijnlijk in het midden van 2015 met een nieuw richtlijnvoorstel. Het nieuwe richtlijnvoorstel is mogelijk een afge- zwakte vorm van de FTT, waarbij in ieder geval pensioenfondsen en overheidsobligaties worden vrijgesteld van de heffing (Jones, 2013).

Sinds het oorspronkelijke richtlijnvoorstel uit 2011 hebben verschillende EU-landen een nationale bankenbelasting ingevoerd, waaronder Nederland. Onze bankenbelasting is ingevoerd per 1 oktober 2012. Hoewel de doelstellingen overlap vertonen met de doelstellingen van de FTT is de wijze van heffing anders. De Nederlandse bankenbelasting belast namelijk het balanstotaal verminderd met een aantal onderdelen van de passivazijde van de balans. Een doelmatigheidsvrijstelling zorgt dat alleen de systeembanken worden getroffen. De Nederlandse bankenbelasting is robuust en eenvoudig (Van der Doelen \& Storm van 's Gravesande, 2013, p. 893). Het kleine aantal belastingplichtigen makkt dat de uitvoeringslast voor de overheid beperkt is. Door in de wet voornamelijk aan te sluiten bij uit de jaarrekening afkomstige bepalingen is de administratieve last voor de belastingplichtigen eveneens overzichtelijk.

De belangrijkste doelstelling die de Europese Commissie in haar voorstel voor de FTT heeft benoemd, is het ontmoedigen van speculeren op financiële markten waardoor de Europese financiële sector transparanter en stabieler wordt (European Commission, 2013, p. 4). Verschillende economen hebben vanaf de jaren '70 van de vorige eeuw het effect onderzocht van een belasting op financiële transacties op de stabiliteit van de financiële sector. De studies van deze economen behandelen we in dit artikel. De door hen onderzochte stabiliteit komt tot uitdrukking in een lage volatiliteit (mate van beweeglijkheid) van de aandelenprijzen. Hoe hoger de volatiliteit is van een aandeel, hoe onzekerder de waarde is.

Wanneer kan worden aangetoond dat de FTT het bereiken van stabiliteit in de financiële sector bevordert, wordt het aantrekkelijk voor Nederland om deel te nemen aan deze EU-brede belasting. In dit artikel wordt de volgende probleemstelling gehanteerd: In hoeverre zal de invoering van de Europese financiële transactiebelasting destabiliserende financiële transacties ontmoedigen en bijdragen aan een verlaging van de volatiliteit van financiële markten? Voor de analyse van de Europese FTT is gebruik gemaakt van het meest recente richtlijnvoorstel uit februari 2013. 
Dit artikel is als volgt opgebouwd. Paragraaf twee geeft een overzicht van de werking van de Europese FTT en beschrijft de doelstellingen van deze belasting. In paragraaf drie wordt de belangrijkste doelstelling van de Europese FTT toegelicht aan de hand van belangrijke begrippen uit de internationale financiële economie. Paragraaf vier vat verschillende economische studies samen, die de relatie hebben onderzocht tussen de invoering van een financiële transactiebelasting en de volatiliteit in aandelenprijzen. Hierbij worden de voor- en tegenstanders van een financiële belasting tegenover elkaar gezet. Tot slot worden in paragraaf vijf de belangrijkste bevindingen weergegeven en benoemen wij aandachtspunten voor de toekomst.

\section{Europese financiële transactiebelasting 2.1 Werking van de Europese FTT}

De subjecten van heffing van de FTT zijn in beginsel alle financiële instellingen die gevestigd zijn in een EUlidstaat (zowel deelnemende als niet-deelnemende lidstaten aan de FTT) en die betrokken zijn bij financiële transacties waarbij minstens één betrokken partij gevestigd is in een deelnemende EU-lidstaat (European Commission, 2013, p. 23). Een financiële instelling die niet in een EU-lidstaat is gevestigd, kan ook in de heffing worden betrokken indien het onderliggende financiële instrument is uitgegeven door een partij in een EU-lidstaat die deelneemt aan de FTT. De Europese Commissie hanteert een brede definitie van financiele instellingen. Hieronder vallen onder andere: investeringsbedrijven, kredietinstellingen, verzekeringsmaatschappijen, pensioenfondsen en natuurlijke personen die financiële activiteiten met een aanzienlijke waarde verrichten (European Commission, 2013, p. 9). Nationale centrale banken en de Europese Centrale Bank (ECB) zijn vrijgesteld van de belasting (European Commission, 2013, p. 23). Een voorbeeld ter verheldering van het voorgaande is een Amerikaanse bank die een aandeel in een Duits bedrijf verkoopt aan een andere Amerikaanse bank. Hoewel de Verenigde Staten geen EU-lidstaat is, wordt de verkopende partij in de VS toch in de heffing betrokken, omdat het verhandelde financiële instrument is uitgegeven door een aan de FTT deelnemende lidstaat, in dit geval Duitsland.

De objecten van heffing voor de FTT zijn de koop/ verkoop en overdracht van financiële instrumenten. Financiële instrumenten bestaan uit verhandelbare effecten, zoals aandelen en obligaties, en financiële derivaten, zoals opties, futures, swaps en forwards (European Commission, 2013, p. 20). Effecten zijn verhandelbare rechten die een financiële waarde vertegenwoordigen en deze worden veelal op een beurs verhandeld, waarbij de koers wordt bepaald door vraag en aanbod. Derivaten zijn beleggingsinstrumenten die hun waarde ontlenen aan de waarde van een ander goed, zoals olie en de wisselkoers van valuta (Pilbeam, 2006, p. 324). In aanvulling op de vrijstelling voor transacties van nationale EU-banken en de ECB worden financieringsactiviteiten van bedrijven, zoals aandelenemissies, niet in de heffing betrokken. Ook het afsluiten van een hypotheek of verzekeringscontract door burgers of bedrijven, is vrijgesteld van de Europese FTT (European Commission, 2013, p. 15).

Het heffingsmoment is het moment waarop de transactie plaatsvindt. De FTT dient te worden betaald binnen drie dagen nadat de transactie heeft plaatsgevonden. Dit is dus een forse verhoging van de administratieve lasten. Bovendien is een aansprakelijkheidsstelling opgenomen. Als een belastingplichtige buiten de FTT zone de verschuldigde FTT niet binnen drie dagen betaalt, dan dient de tegenpartij binnen de FTT zone alsnog de belasting af te dragen (European Commission, 2013, pp. 12-13).

De maatstaf van heffing voor de FTT is, met uitzondering van derivaten, de prijs die overeengekomen is tussen de betrokken partijen bij een transactie. Indien deze prijs niet marktconform is of indien er geen koop of verkoop plaatsvindt, is de maatstaf van heffing in het eerste geval de marktprijs op het moment van het ontstaan van de belastingclaim (European Commission, 2013, p. 25). In het tweede geval bestaat zo'n marktprijs niet. Voor het bepalen van de maatstaf van heffing wordt dan gekeken naar hetgeen onafhankelijke derden in soortgelijke omstandigheden elkaar zouden berekenen (de zogenoemde arm's length price). In het geval van een transactie met derivaten is de maatstaf de nominale waarde van de derivaten op het moment van de financiele transactie (European Commission, 2013, p. 26).

De tarieven verschillen voor derivaten en niet-derivaten. Het minimumtarief voor derivatentransacties bedraagt 0,01\%, voor effectentransacties 0,1\% (European Commission, 2013, p. 26). Dit onderscheid in tarieven heeft als reden dat de Europese Commissie verschillende reacties van de derivaten- en effectenmarkten verwacht op de invoering van de Europese FTT. Door het onderscheid in tarieven wordt de belastingdruk over de twee markten ongeveer gelijk getrokken (European Commission, 2013, pp. 26-27). Deelnemende EU-lidstaten mogen hiervan afwijken en hogere tarieven vaststellen.

\subsection{Doelstellingen van de Europese FTT}

Het oorspronkelijk richtlijnvoorstel was een directe respons op de financiële crisis die begon in het najaar van 2007. Volgens het voorstel is de financiële sector voornamelijk verantwoordelijk voor het ontstaan van de financiële crisis door het nemen van overmatige risico's. Overheden en burgers hebben in verschillende EU-lidstaten de uitgaven van de crisis moeten dragen (European Commission, 2013, p. 2). Financiële instellingen werden genationaliseerd en er werd staatsteun verleend. Daarnaast is de Europese Commissie van mening dat 
de financiële sector in de EU sinds 1968 onderbelast is geweest door de vrijstelling van art. 135 lid 1 in de Btwrichtlijn, waardoor financiële instellingen zijn vrijgesteld van het betalen van btw. Het vrijstellen van de financiële sector heeft geleid tot een lagere belastingheffing in vergelijking met andere sectoren, hetgeen een fiscale voorkeursbehandeling van deze sector impliceerde (European Commission, 2013, p. 1). Binnen de EU wordt gepleit voor een eerlijker verdeling van de kosten van de crisis. De implementatie van de Europese FTT geeft gehoor aan deze ontwikkelingen en op basis hiervan zijn de volgende drie politieke doelstellingen opgesteld (European Commission, 2013, p. 2):

Doelstelling 1. Het ontmoedigen van speculeren op de financiële markten, waardoor de Europese financiële sector transparanter en stabieler wordt;

Doelstelling 2. Het harmoniseren van nationale wetgevingen, betgeen bijdraagt aan het functioneren van een interne markt voor transacties in financiële instrumenten en het vermijden van concurrentie binnen de EU;

Doelstelling 3. Een extra inkomstenbron creëren voor de EU die kan bijdragen aan de begroting van de nationale lidstaten (de verwachte opbrengst is op jaarbasis 30 à 35 miljard euro).

Over de realisatie van doelstelling 2 en 3 hebben we weinig twijfels. Er is een aantal lidstaten dat een nationale bankenbelasting heeft ingevoerd. Dit bevordert de interne markt natuurlijk niet en bovendien neemt de kans op dubbele belastingheffing toe. De verschillende bankenbelastingen kunnen namelijk leiden tot het tweemaal belasten van dezelfde transactie of balanspost. Bij de invoering van een Europese belasting wordt dat in ieder geval binnen Europa voorkomen. Voorwaarden hiervoor zijn het verbod van een nationale bankenbelasting en de implementatie van de FTT in iedere EU-lidstaat. Tot op heden is er overigens nog maar zeer beperkt opgetreden tegen het voorkomen van dubbele belasting. In Nederland is het Besluit ter Voorkoming van Dubbele Belasting (BvdB 2001) aangepast, maar verder is alleen met het Verenigd Koninkrijk een verdrag gesloten ter voorkoming van dubbele bankenbelasting (Ministerie van Financiën, 2013). Daarnaast is in het voorstel van de Europese Commissie (nog) geen regeling getroffen om dubbele belastingheffing tegen te gaan, wanneer financiële instellingen buiten de EU worden geconfronteerd met een FTT. De invoering van een Europese FTT vergroot in ieder geval het gelijke speelveld binnen de EU en versterkt daarmee de interne markt.

Ook zorgt de invoering van de FTT voor een extra inkomstenbron in de EU, die deels kan bijdragen in de EU-begroting van de nationale lidstaten. De verwachte opbrengsten zijn berekend op basis van het aantal deelnemende landen tot op heden. Deze opbrengsten zullen gedeeltelijk onderdeel zijn van de EU-begroting, waarbij het resterende deel toevloeit naar de deelnemende lidstaten (European Commission, 2013, p. 15). Hoewel de concrete uitwerking nog onduidelijk is, hebben wij de meeste zorgen over de realisatie van doelstelling 1 . Voor het vervolg van dit artikel gaan we in op de economische theorieën en papers die betrekking hebben op de eerste doelstelling van de FTT.

\section{Belangrijke begrippen uit de internationale financiële eco- nomie}

De volatiliteit geeft de mate van beweeglijkheid van de aandelenkoers weer of de prijs van een ander financieel product gedurende een bepaald tijdsinterval en is daardoor een maatstaf van de stabiliteit van de desbetreffende markt (Pilbeam, 2006, p. 137). Stabiele financiële markten zijn wenselijk, omdat de welvaart in een land gebaat is bij een efficiënt werkende kapitaalmarkt. In perfect werkende kapitaalmarkten wordt de volatiliteit van een financieel product (obligaties, aandelen, derivaten) volledig gedreven door de fundamentele waarde van het financieel product. De fundamentele waarde komt tot stand door beslissingen en verwachtingen van vragers en aanbieders, die over alle relevante informatie beschikken betreffende een onderneming (Pilbeam, 2006, p. 203). Hierdoor kunnen marktparticipanten de toekomstige winstgevendheid van de onderneming perfect inschatten, zodat hun kapitaal kan worden gealloceerd aan investeringen die het beste passen bij hun risicobereidheid.

Echter, de fundamentele waarde kan onmogelijk worden ingeschat omdat in de werkelijkheid niet alle relevante informatie beschikbaar is. Hierdoor kunnen sommige marktparticipanten kortetermijnwinsten behalen door sneller dan anderen een trend te herkennen in en te anticiperen op de valuta- en aandelenkoersen. Deze groep marktparticipanten worden speculanten genoemd, die telkens aandelen (of andere financiële producten) inkopen, wanneer de fundamentele waarde hoger is dan de marktprijs, of verkopen, wanneer de fundamentele waarde lager is dan de marktprijs. Speculanten kunnen worden verdeeld in twee groepen, de high frequency traders en de arbitrageurs. High frequency traders zijn flitshandelaren die met behulp van algoritmen en wiskundige modellen in zeer korte tijd anticiperen op kleine wijzigingen in valuta- en aandelenkoersen. De winst per transactie is zeer beperkt, maar de omvang van de hoeveelheid transacties gigantisch. Arbitrageurs profiteren van prijsverschillen van (aan elkaar gerelateerde) effecten die worden verhandeld op verschillende markten. Denk bijvoorbeeld aan een aandeel dat is genoteerd in zowel Amsterdam als New York. Als het aandeel in Amsterdam hoger genoteerd staat, verkoopt een arbitrageur dit aandeel en koopt het aandeel dat in New York is genoteerd met de verwachting dat dit aandeel gaat stijgen naar de Amsterdamse prijs. 
Enerzijds hebben high-frequency traders een destabiliserend effect op de volatiliteit, omdat het anticiperen op koersbewegingen trendversterkend is. Dit resulteert in excessieve volatiliteit, hetgeen de onzekerheid bij beleggers vergroot en een efficiënte werking van de kapitaalmarkten belemmert (Pilbeam, 2006, pp. 23-24). Ook heeft deze vorm van speculeren geen toegevoegde waarde voor de samenleving, omdat winst voor één partij verlies oplevert voor de ander. Anderzijds hebben arbitrageurs een stabiliserend effect op de volatiliteit, omdat risicoloze kortetermijnwinsten worden behaald door te profiteren van prijsverschillen op verschillende beurzen. Het bestaan van arbitrageurs zorgt ervoor dat dezelfde effecten (obligaties, aandelen) op verschillende beurzen dezelfde prijs hebben, hetgeen een efficiënte werking van de kapitaalmarkten bevordert (Pilbeam, 2006, p. 21).

Ons huidige internationaal financieel systeem kent een hoge kapitaalmobiliteit, waarbij grote kapitaalstromen met relatief lage transactiekosten in korte tijd tussen landen bewegen. De excessieve kapitaalmobiliteit heeft geleid tot een stijging in de valuta- en aandelenspeculatie, in het bijzonder tot een enorme toename in de flitshandel (Pilbeam, 2006, pp. 87-89). In de Verenigde Staten bestaat ongeveer tweederde van de totale aandelenhandel in 2010 uit flitshandel (Biais \& Woolley, 2011, p. 2). Flitshandelaren nemen de grote risico's en de destabiliserende effecten op de kapitaalmarkten op de koop toe. Aldus beoogt de Europese Commissie met de financiële transactiebelasting een aanzienlijke vermindering van de risicovolle flitshandel, waardoor de Europese financiële sector stabieler en bestendiger wordt voor toekomstige financiële crises.

\section{Financiële transactiebelasting en volatiliteit aandelenprijzen}

In deze paragraaf worden verschillende economische studies besproken die de relatie hebben onderzocht tussen het invoeren van een financiële transactiebelasting en de stabiliteit van financiële markten. Grofweg zijn er twee stromingen die een tegenovergestelde visie aanhouden op het effect van een financiële transactiebelasting op de volatiliteit van de aandelenprijzen.

Zowel John Maynard Keynes (1936) als Milton Friedman (1953) beargumenteren dat de invoering van een financiële transactiebelasting de transactiekosten verhoogt: korte termijntransacties worden onrendabel, waardoor zowel flitshandelaren als arbitrageurs de markt zullen verlaten. Hierdoor daalt het totale transactievolume en de liquiditeit, omdat er minder kapitaal beschikbaar wordt gesteld. Vervolgens verschilt de gedachtegang van de twee economen. Keynes benadrukt vooral de destabiliserende rol van flitshandelaren op de kapitaalmarkten, waardoor een financiële transactiebelasting resulteert in een daling van de volatiliteit van de financiële markten en een stabiele financiële sector. Speculatie wordt teruggedrongen ten gunste van investe- ringen op lange termijn (Keynes, 1936, p. 143). Daarentegen beargumenteert Friedman de stabiliserende rol van arbitrageurs, die een sterker effect hebben op de aandelenprijzen dan de destabiliserende flitshandelaren. Wanneer de invoering van een financiële transactiebelasting zorgt voor een sterkere afname in stabiliserende speculaties dan destabiliserende speculaties, kan de volatiliteit van aandelenprijzen juist toenemen. Daarom acht Friedman elke vorm van financiële transactiebelasting ongewenst, omdat de invoering ervan kan leiden tot een minder stabiele financiële sector (Friedman, 1953, pp. 159-205). Het mag duidelijk zijn dat het richtlijnvoorstel van de Europese Commissie gebaseerd is op de benadering van Keynes.

Vanaf de jaren '70 van de vorige eeuw hebben verschillende economen de relatie onderzocht tussen de invoering van een financiële transactiebelasting en volatiliteit van de financiële markten. Er zijn zowel auteurs die de effecten van een financiële transactiebelasting hebben onderzocht voor de valutamarkt (Tobin, 1978; Aliber, Chowdhry \& Yan, 2003) als voor de effectenmarkt (Stiglitz, 1989; Paling \& Vrijburg, 2013; Umlauf, 1993). Daarnaast werd de Nederlandse beursbelasting geheven van de effectenhandelaar die zijn bedrijf in Nederland uitoefende (Fiscale Encyclopedie, 2010a). Hoewel de FTT heeft voorgenomen om financiële transacties in de effecten- en derivatenmarkt in de heffing te betrekken, worden de papers die betrekking hebben op de valutamarkt ook nadrukkelijk besproken in dit artikel. Immers, de FTT vertaalt zich, vanuit economisch oogpunt, in hogere transactiekosten voor marktparticipanten, hetzij op de valutamarkt, hetzij op de aandelenmarkt. Ook bouwen alle onderzoeken voort op de theorie achter Tobin (1978), die de effecten van een financiële transactiebelasting op de volatiliteit van de belangrijkste wisselkoersen heeft onderzocht. Voor het vervolg van deze paragraaf komen eerst drie papers aan bod die pleiten voor de benadering van Keynes, daarna worden twee empirische onderzoeken besproken die voortbouwen op de benadering van Friedman.

\subsection{Afname volatiliteit kapitaalmarkten (Keynes)}

In 1972 publiceerde Nobelprijswinnaar James Tobin zijn theorie achter de Tobintax. De excessieve kapitaalmobiliteit door afschaffing van het Bretton Woods systeem ${ }^{2}$ leidde tot meer valutaspeculaties en een hogere wisselkoersvolatiliteit van verschillende wisselkoersen. Een belasting die internationale valutatransacties belastte, zou de volatiliteit van de wisselkoersen tussen de belangrijkste valuta's verlagen (Tobin, 1978, p. 154). Het tarief moest uniform zijn in alle deelnemende landen. Daarnaast zouden nationale overheden door de Tobintax controle over nationaal economisch en fiscaal beleid terugwinnen. Immers, internationale mo- 
biliteit van valuta en andere financiële instrumenten belemmert het uitvoeren van monetair en fiscaal beleid door nationale centrale banken en overheden (Tobin, 1978, p. 159). Volledigheidshalve dient te worden opgemerkt dat het bereik van de Europese FTT vele malen groter is dan de Tobintax: de Tobintax belast enkel valutatransacties op de valutamarkt terwijl de Europese FTT zowel effecten- als derivatenmarkt in de heffing zal betrekken.

De Amerikaanse Nobelprijswinnaar Joseph

Stiglitz onderzocht in 1989 de wenselijkheid van een belasting op financiële transacties voor de effectenmarkt. Hij beweert dat de efficiëntie van de financiële markten enerzijds verbetert doordat de belasting beleggers ontmoedigt om excessieve uitgaven te doen om kortetermijnwinsten te behalen. Anderzijds wordt de efficiëntie geschaad omdat transactiekosten toenemen. Echter zullen lange termijn beleggers hier nauwelijks last van ondervinden. Het zijn korte termijn speculanten die de markt verlaten, wat zorgt voor een lagere liquiditeit van de kapitaalmarkten. Stiglitz concludeert dat de liquiditeitsvermindering niet hoeft te leiden tot een hogere volatiliteit. De meeste arbitrageurs blijven in de markt, omdat ze verwachten dat speculeren nog steeds winstgevend zal zijn (Stiglitz, 1989, p. 110). Empirisch onderzoek wijst uit dat een transactiebelasting de volatiliteit op de aandelenmarkt kan verlagen (Stiglitz, 1989, pp. 110-111). Tot slot beweert Stiglitz dat het tarief voor opties (derivaten) de helft zou moeten zijn van het tarief op aandelen (effecten), om marktverstoringen te voorkomen (Stiglitz, 1989, p. 112). Het kan om deze reden zijn geweest dat de Europese Commissie een lager tarief heeft voorgesteld voor derivaten $(0,01 \%)$ dan voor effecten $(0,1 \%)$.

Nederland heeft in de periode 1972-1990 een eigen variant op de Tobintax gekend, namelijk de beursbelasting. Deze belasting is ingevoerd met als doel om bij te dragen in de algemene middelen van de overheid (Kamerstukken II, 1979/70, 10 560, nr. 3, p. 15). De belasting werd geheven van de effectenhandelaar die voor privé- of bedrijfsdoeleinden effecten aankocht of verkocht binnen Nederland (Fiscale Encyclopedie, 2010a). Het tarief van de beursbelasting bedroeg $0,12 \%$ over het voldane bedrag bij de aan- of verkoop van effecten, waarbij in bijzondere situaties een tariefsverlaging was toegestaan naar $0,03 \%$. Het betrof situaties waarbij koper en verkoper al tot overeenstemming zijn gekomen over de effectentransactie zonder de bemiddeling van de betrokken effectenhandelaar (Fiscale Encyclopedie, 2010b). De belangrijkste reden voor afschaffing van de beursbelasting op 1 juli 1990 was de toenemende concurrentieverstoring, die een negatieve impact zou hebben op de Amsterdamse effectenbeurs (Kamerstukken II, 1989/90, 21 342, nr. 3, p. 5). Immers, in 1988 ver- schoof meer dan de helft van de Nederlandse effectenhandel naar het Verenigd Koninkrijk, waar effectentransacties niet werden belast. Daarnaast zou de afschaffing van de beursbelasting leiden tot hogere vennootschapsbelastingopbrengsten (Kamerstukken II, 1989/90, 21342 , nr. 3, p. 4).

Paling en Vrijburg hebben in 2013 in een empirische studie de relatie tussen de afschaffing van de beursbelasting en de volatiliteit van AEX-aandelen onderzocht. Ze concluderen dat de afschaffing van de beursbelasting op 1 juli 1990 de volatiliteit van de AEX-aandelen met $8 \%$ heeft laten toenemen, ondanks het feit dat de belasting door veel effectenhandelaren werd ontweken (Paling \& Vrijburg, 2013, p. 201). Omdat de Europese FTT veel gelijkenissen vertoont met de Nederlandse beursbelasting, beweren de auteurs dat de invoering van de FTT de potentie heeft om de volatiliteit van de AEX-aandelen te laten afnemen, wat bij kan dragen aan een stabielere financiële sector in Nederland (Paling \& Vrijburg, 2013, p. 198). Opgemerkt moet worden dat de beursbelasting relatief gemakkelijk te ontwijken was, omdat alleen de effectenhandel die plaatsvond in Nederland werd belast. Aangezien het moeilijker is voor financiële instellingen om de Europese FTT te ontwijken, zal het voorspelde effect van de belasting op de volatiliteit van de AEX-aandelen aanzienlijk groter zijn dan de eerder genoemde $8 \%$. Daarnaast hebben de auteurs het effect van de afschaffing van de beursbelasting op de volatiliteit van aandelen onderzocht, en niet het effect van de invoering van de belasting. Wellicht kan de afschaffing van een belasting andere effecten hebben op de aandelenvolatiliteit dan de invoering ervan, waardoor het effect van de Europese FTT op de aandelenvolatiliteit vooralsnog onduidelijk is.

\subsection{Toename volatiliteit kapitaalmarkten (Friedman)}

Umlauf gebruikte in 1993 de data van de Zweedse aandelenmarkt uit de jaren '80 om aan te tonen dat de introductie van een Tobintax in Zweden niet leidde tot een vermindering van speculaties door flitshandelaren. Hij concludeerde dat de financiële transactiebelasting leidde tot een significante verhoging van de volatiliteit in de Zweedse aandelenmarkt in de jaren 1980-1987 (Umlauf, 1993, pp. 227-228). De tariefsverhoging (van $1 \%$ in 1984 naar $2 \%$ in 1986) zorgde namelijk voor een verschuiving van $60 \%$ van het transactievolume van de belangrijkste Zweedse aandelen naar Londen (Umlauf, 1993, p. 229). Naast het effect op de verhoogde volatiliteit, heeft de sterke daling in het transactievolume ook gevolgen voor de overheidsfinanciën. De opbrengsten van de belasting na de tariefsverhoging vielen weg tegen de vermindering van de effectenhandel, waardoor de belastingopbrengsten vrijwel gelijk bleven (Umlauf, 1993, p. 229). Vooral transacties in obligaties van de Zweedse overheid werden hard getroffen en men was genood- 
zaakt om deze transacties vrij te stellen van heffing. Kortom, het empirisch onderzoek concludeerde dat de daadwerkelijke belastingopbrengsten van de tariefsverhoging nihil bedroegen, terwijl de volatiliteit van de financiële markt is toegenomen en een destabiliserend effect had op de Zweedse economie. In het verlengde hiervan vrezen wij negatieve gevolgen voor de handel in Europese obligaties en de Nederlandse in het bijzonder.

De empirische studie van Aliber, Chowdhry en Yan uit 2003 levert ook bewijs tegen de Tobintax. Gebruikmakend van een aangepast model dat de transactiekosten van de investeerders schat, vinden de auteurs een positief verband tussen een stijging van de transactiekosten en de beweging van de volatiliteit in de vier onderzochte wisselkoersen voor de periode 1977-1999. ${ }^{3}$ Ze schatten dat een Tobintax van $0,02 \%$ leidt tot een stijging van de volatiliteit van de wisselkoersen met $0,5 \%$ (gemiddeld ligt deze volatiliteit tussen $10 \%$ en $12 \%$ ). In hun model heeft de Tobintax een daling van het transactievolume met 2.000 transacties per dag tot gevolg (gemiddeld ligt het dagelijkse transactievolume tussen 8.000 en 20.000 transacties). Het onderzoek is afgesloten met de opmerking dat men voorzichtig moet zijn om geheel te vertrouwen op de theorie van Tobin, omdat de Tobintax mogelijkerwijze juist leidt tot een stijging in de volatiliteit van de wisselkoersen (Aliber e.a., 2003, p. 509).

\section{Conclusies en discussie}

In de inleiding van dit artikel werd gesteld dat het ontmoedigen van speculeren op financiële markten de belangrijkste doelstelling is van de Europese financiële transactiebelasting.

Een analyse van economische studies laat echter niet eenduidig zien of de invoering van de FTT leidt tot een stabiele financiële sector in Europa. Het staat vast dat belastingen op financiële transacties resulteren in hogere transactiekosten voor marktparticipanten en lagere transactievolumes van zowel effecten als derivaten. Zowel destabiliserende flitshandelaren als stabiliserende arbitrageurs verlaten vervolgens de markt. De doelstelling van de FTT is gericht op het ontmoedigen van destabiliserende speculaties van flitshandelaren, terwijl stabiliserende arbitrageurs ook worden geraakt door de belasting. In hoeverre deze belasting bijdraagt aan een lagere volatiliteit van de financiële markten hangt af van de effecten op flitshandelaren en arbitrageurs. Juist omtrent dit punt verschaffen de besproken economische studies geen eenduidig antwoord. Daarnaast leidt het lagere transactievolume onvermijdelijk tot concurrentieverstoringen tussen zowel deelnemende en niet-deelnemende landen, als tussen de deelnemende landen onderling (door middel van tariefsconcurrentie). De belangrijkste reden voor de afschaffing van de beursbelas- ting, de Nederlandse variant van de Tobintax in de jaren 1972-1990, was dan ook de negatieve invloed van de beursbelasting op de Amsterdamse effectenbeurs door toenemende concurrentieverstoringen.

Daarentegen harmoniseert de FTT bestaande, nationale wetgevingen voor financiële transacties hetgeen bijdraagt aan vergroting van het gelijke speelveld en de versterking van de interne markt in de deelnemende EU-landen. Voorwaarde is wel dat het hebben van een nationale bankenbelasting verboden moet worden als er een Europese FTT wordt ingevoerd. De huidige situatie waarin verschillende lidstaten ieder een eigen nationale bankenbelasting hebben ingevoerd werkt verstorend. Het risico op dubbele belastingheffing is bovendien toegenomen. Wel moeten we opmerken dat zolang er geen mondiale heffing wordt ingevoerd voor financiële transacties concurrentie tussen landen blijft bestaan en financiële transacties mogelijk verplaatsen.

Nederland kan besluiten om toe te treden, wanneer het nieuwe richtlijnvoorstel met de afgezwakte vorm van de financiële transactiebelasting wordt gepubliceerd. Dit wordt met name interessant als tegen die tijd meer EU-landen besluiten deel te nemen aan de financiële transactiebelasting en als het nieuwe richtlijnvoorstel aan de nader gestelde voorwaarden in het regeerakkoord van kabinet Rutte-II voldoet (Kamerstukken II, 2012/2013, 1336 , p. 1). ${ }^{4}$ Gegeven de verwachting dat er voldoende maatschappelijk draagvlak bestaat om de financiële sector te belasten, moeten politici beoordelen of de voordelen van de belasting op financiële transacties (en het afschaffen van de huidige bankenbelasting) opwegen tegen de extra kosten die gemoeid zijn bij de implementatie ervan. De maatschappelijke wens is dat de financiële sector een bijdrage levert in ruil voor de verstrekte steun ten tijde van de crisis. Uit de besproken onderzoeken concluderen wij dat de Europese financiële transactietax het leveren van deze bijdrage ondersteunt. De verwachtingen omtrent het verlagen van de aandelenvolatiliteit en het versterken van de risicobeheersing van banken dienen echter wat getemperd te worden.

Mw. M.Q. de Vries BSc. heeft Fiscale Economie en Economie \& Bedrijfskunde gestudeerd aan de Universiteit van Amsterdam en is inmiddels werkzaam bij de Belastingdienst.

Mw. mr. drs. N.G.H. Speet RA is verbonden aan de sectie Fiscale Economie van de Economische faculteit van de Universiteit van Amsterdam. Daarnaast is zij werkzaam bij de Belastingdienst Grote Ondernemingen. Zij schrijven dit artikel op persoonlijke titel. 
1 Tot op heden hebben de volgende landen een deelname aan de FTT toegezegd: België, Duitsland, Estland, Griekenland, Spanje, Frankrijk, Italië, Oostenrijk, Portugal, Slovenië en Slowakije.

2. Het systeem van Bretton Woods was een stelsel van vaste wisselkoersen, waarin de waarde van 44 verschillende nationale valuta gekoppeld werd aan die van de dollar, waaronder de
Nederlandse gulden. Vervolgens kon de dollar tegen een vaste hoeveelheid goud worden ingewisseld bij de Amerikaanse Centrale Bank.

3 De vier gebruikte wisselkoersen zijn: Duitse Mark, Japanse Yen, Zwitserse Franc en Britse Pond. 4 In het regeerakkoord zijn drie randvoorwaarden gesteld waaraan Europese FTT moet voldoen:
1. pensioenfondsen mogen geen schade ondervinden van de belasting;

2. er mag geen disproportionele samenloop zijn met de huidige Nederlandse bankenbelasting;

3. de inkomsten uit de belasting moeten terugvloeien naar de deelnemende lidstaten.

\section{Literatuur}

- Aliber, R., Chowdhry, B., \& Yan, S. (2003). Some evidence that a Tobin tax on foreign exchange transactions may increase volatility. European Finance Review, 7(3), 481-510.

- Biais, B. \& Woolley, P. (2011). High frequency trading. Manuscript, Toulouse University, IDEl. Geraadpleegd op: http://idei.fr/doc/conf/pwri/ biais_pwri_0311.pdf.

- Doelen, S.G.J.W. van der, \& Storm van 's Gravesande, L.H. (2013). Bankenbelasting: robuust en eenvoudig? Weekblad voor Fiscaal Recht, 2013/893.

- European Commission (2013). Proposal for a Council Directive: Implementing enhanced cooperation in the area of financial transaction tax. COM (2013) 71 final. Geraadpleegd op http://ec.europa.eu/taxation_customs/resources/documents/taxation/com_2013_71_en. pdf.

- Fiscale Encyclopedie (2010a). De Vakstudie Belastingen van rechtsverkeer, 1 Afschaffing beursbelasting bii: Wet op belastingen van rechtsverkeer, Artikel 40. Geraadpleegd op http://deeplinking.kluwer. nl/?param =00347993.

- Fiscale Encyclopedie (2010b). De Vakstudie Belastingen van rechtsverkeer, 1 Tarief bij: Wet op belastingen van rechtsverkeer, Artikel 44. Geraadpleegd op http://deeplinking.kluwer.nl/?param=0034789F.

- Friedman, M. (1953). The case for flexible exchange rates. In M. Friedman, Essays in positive economics (pp. 159-205), Chicago: The University of Chicago Press.

- Jones, H. (2013). Update 1 - Eleven EU states to consider narrower transaction tax. Reuters, 11 december 2013.

- Kamerstukken II, 1979/70, 10 560, nr. 3.

- Kamerstukken II, 1989/90, 21 342, nr. 3

- Kamerstukken II 2012/13, 1336 (Aanhangsel van de Handelingen).

- Keynes, J.M. (1936/2008). The general theory of employment, interest and money. New Delhi: Atlantic Publishers \& Distributors.

- Ministerie van Financiën (2013). Weekers tekent verdrag ter voorkoming dubbele ban- kenbelasting met Verenigd Koninkrijk. Geraadpleegd op http://www.rijksoverheid.nl/ nieuws/2013/06/12/weekers-tekent-verdragter-voorkoming-dubbele-bankenbelastingmet-vk.html?ns_campaign=nieuwsberichtenover-het-onderwerp-belastingeninternationaal\&ns_channel=att.

- Paling, M., \& Vrijburg, H. (2013). Financiële transactiebelasting en volatiliteit aandelenmarkten. Economisch Statistische Berichten, 98(4657), 198-201.

- Pilbeam, K. (2006). International finance. New York: Palgrave Macmillan.

- Stiglitz, J. E. (1989). Using tax policy to curb speculative short-term trading. Journal of Financial Services Research, 3(2-3), 101-115.

- Tobin, J. (1978). A proposal for international monetary reform. Eastern Economic Journal, 29(4), 519-526.

- Umlauf, S. R. (1993). Transaction taxes and the behavior of the Swedish stock market. Journal of Financial Economics, 33(2), 227 240. 